\title{
Effect of fasting on lipid metabolism and oxidative stability in fattening chicken fed a diet supplemented with organic selenium
}

\author{
Blanka Beer-Ljubić', Jasna Aladrović1, Suzana Milinković-Tur', Maja Lazarus² and Ivan \\ Pušić ${ }^{3}$ \\ 'Department of Physiology and Radiobiology, Faculty of Veterinary Medicine, University of Zagreb, Zagreb, Croatia, \\ ${ }^{2}$ Analytical Toxicology and Mineral Metabolism Unit, Institute of Medical Research and Occupational Health, Zagreb, \\ Croatia, ${ }^{3}$ Ministry of Environmental Protection, Physical Planning and Construction, Zagreb, Croatia
}

\begin{abstract}
The aim of the study was to assess the effect of organic selenium dietary supplementation on serum and tissue lipid composition after fattening period and after $48 \mathrm{~h}$ fasting in fattening chicken. The study was performed in the Ross hybrid line chicken divided into two groups: control group fed standard diet and Sel Plex group fed standard diet supplemented with $0.3 \mathrm{ppm}$ organic selenium. Blood, liver, intestine and adipose tissue samples were taken upon fattening completion and after $48 \mathrm{~h}$ fasting. Total cholesterol, high-density lipoprotein (HDL) cholesterol, low-density lipoprotein (LDL) cholesterol, triacylglycerol and lipoprotein concentrations were determined in serum, whereas total and free cholesterol, triacylglycerol, lipid peroxide and selenium concentrations and glutathione peroxidase activity (GSH-Px) were determined in tissue samples. During fattening period, the correlation of organic selenium with lipid metabolism manifested as decreased concentrations of serum triacylglycerols and very-low-density lipoprotein (VLDL) $(P<0.05)$, liver triacylglycerols $(P<0.05)$, adipose tissue cholesterol $(P<0.05)$ and small intestine cholesterol $(P<0.05)$, and reduced lipid peroxidation $(P<0.05)$. Upon chicken exposure to $48 \mathrm{~h}$ fasting, organic selenium supplementation resulted in increased free cholesterol concentration in adipose tissue $(P<0.05)$, GSH-Px activity in the liver $(P<0.05)$, and selenium $(P<0.05)$ accumulation in the liver.
\end{abstract}

Keywords: organic selenium, glutathione peroxidase, lipid peroxides, cholesterols, triacylglycerols

\section{Introduction}

Oxidative stress refers to impairment in the oxidative and antioxidative compound balance, which is due to either a reduced intake or synthesis of antioxidative molecules, or to an increased synthesis of oxidative compounds. Various models have been used to investigate the causes and consequences of oxidative stress, e.g., environmental hypothermia (GradinskiVrbanac et al. 1999) or hyperthermia (Mahmoud \& Edens 2003), animal exposure to physical stress (Tsopanakis \& Tesserommatis 1990), and restrictive feeding and fasting (Lamošová et al. 2004, Milinkovič et al. 2007). Fasting is a form of oxidative stress characterised by mobilisation and consumption of lipid stores. Depending on the length of fasting, lipid concentrations 
vary according to metabolic properties of a particular tissue and organ (Lamošová et al. 2004, Yasuhara et al. 1991). Study results have revealed great differences in the effect of fasting on lipid metabolism in humans (Sävendahl \& Underwood 1999) and animals (Yasuhara et al. 1991).

The intensity of oxidative stress can be monitored by measuring oxidation products or by determination of enzymatic and nonenzymatic antioxidative compounds. Antioxidants protect biological molecules from damages occurring either in physiologic conditions or upon exposure to the action of oxidative compounds. Dietary antioxidants such as vitamins $\mathrm{A}, \mathrm{C}$ and $\mathrm{E}$, and selenium are an important component of antioxidative protection (Temple 2000, Castillo et al. 2001, Kolodziej \& Jacyno 2005, Balicka-Ramisz et al. 2006). Selenium is taken to the body with food in its organic (selenomethionine, selenocysteine) or inorganic (selenates, selenites) form. Organic selenium has shown significantly better antioxidative properties in both mammals (Vinson et al. 1998) and birds (Mahmoud \& Edens 2003). The antioxidative action of organic selenium is elicited through selenoamino acid incorporation into selenoproteins. Selenoproteins, i.e. glutathione peroxidase (GSH-Px) and 5'-diodinase enzymes, influence lipid metabolism in both physiologic and stress conditions. Glutathione peroxidase eliminates hydrogen peroxide and oxidation-altered lipids from tissues, while protecting low-density lipoproteins (LDL) in serum from oxidative changes (Holben \& Smith 1999, Köhrle et al. 2000). The enzyme 5'-deiodinase catalyses synthesis of thyroid hormones, which regulate expression of $L D L$ receptors and apolipoprotein $B$, thus playing a role in maintaining cholesterol level in the circulation (Dhingra \& Bansai 2005).

Studies in hamsters have demonstrated that dietary supplementation with organic selenium reduces the rate of lipoprotein oxidation and cholesterol concentration in serum (Vinson et al. 1998). lizuka et al. (2001) found selenium supplementation to decrease serum triacylglycerol and cholesterol concentrations, as well as hepatic triacylglycerol and cholesterol levels in rats fed cholesterol-rich diet, whereas Dhingra \& Bansal (2005) report on an increased GSH-Px activity and restitution of selenium stores in rat liver.

Some specific features of lipid metabolism in birds, such as lipid synthesis mostly in the liver, intestinal resorption in the form of portomicrons, and specificities of apolipoprotein structure make birds an interesting research model. As fasting is accompanied by changes in lipid metabolism and selenium supplementation influences lipid metabolism in physiological and stress conditions, the aim of the present study was to assess the effect of dietary supplementation with organic selenium on lipid metabolism in chicken serum and some tissues upon completion of fattening period and after $48 \mathrm{~h}$ fasting.

\section{Material and methods}

Animals

The study was performed on the Ross heavy line hybrid chicken of both sexes $(n=100)$. Animals were bred on the floor in the experimental rooms of Department of Physiology and Radiobiology Faculty of Veterinary Medicine University of Zagreb, Croatia. During the first seven days animals were fed a commercial starter diet (crude protein $22 \%$, metabolic energy (ME) $12.85 \mathrm{MJ} / \mathrm{kg}$, Na selenite $0.15 \mathrm{ppm}$ ), then were randomised into two groups: 
control group of animals that continued receiving this diet, whereas experimental (Sel Plex: Alltech, Lexington, KY, USA) group animals received the same diet supplemented with 0.3 ppm organic selenium in the form of selenomethionine from the Sel Plex product. In the subsequent fattening period, animals were fed a standard grower diet (crude protein $20 \%$, ME 12.85 MJ/kg, Na selenate $0.15 \mathrm{ppm}$ ) and finisher diet (crude protein 16\%, ME $12 \mathrm{MJ} / \mathrm{kg}, \mathrm{Na}$ selenate $0.15 \mathrm{ppm}$ ), whereby the same amount of selenium was added to both diets given to control group (Table 1). Both groups were offered feed and water ad libitum until 42 days of age.

Table 1

Diet composition according to manufacturer's specification (Sljeme Animal Feed Industry, Sesvete, Croatia)

\begin{tabular}{lccc}
\hline & Starter diet & Grower diet & Finisher diet \\
\hline Nutrient content & & & \\
Protein min., \% & 22.00 & 20.00 & 16.00 \\
Fat, \% & 5.00 & 5.00 & 5.00 \\
Humidity, \% & 13.0 & 13.5 & 13.5 \\
Raw fiber, \% & 5.00 & 5.00 & 5.00 \\
Calcium, \% & 1.00 & 1.00 & 1.0 \\
Phosphorus min., \% & 0.60 & 0.60 & 0.60 \\
Sodium max., \% & 0.16 & 0.16 & $0.15-0.2$ \\
ME, MJ/kg & 12.85 & 12.85 & 12 \\
Added per kg feed: & & & 50 \\
Manganese min., mg & 100 & 100 & 0.15 \\
Na-selenate min., mg & 0.15 & 0.15 & 50 \\
Zinc min., mg & 80 & 80 & 12000 \\
Vitamin A min., IU & 15000 & 14000 & 2000 \\
Vitamin D3 min., IU & 5000 & 5000 & 25 \\
Vitamin E min., mg & 50 & 50 & 4 \\
Vitamin B min., mg & 8 & 8 & - \\
Coccidiostatic, mg & - & 60 & \\
\hline
\end{tabular}

ME: metabolic energy

At the age of 42 days, blood was sampled by wing vein venepuncture without anticoagulant in both experimental and control animals, then the animals were sacrificed. Immediately upon sacrifice and bleeding, liver, duodenum and adipose tissue were extracted, washed in cold $0.9 \% \mathrm{NaCl}$, wiped with tissue paper, and placed on ice. Upon weighing, organs were stored at $-80^{\circ} \mathrm{C}$ until analysis. The rest of animals were exposed to $48 \mathrm{~h}$ fasting, with water access ad libitum. After $48 \mathrm{~h}$ fasting, sampling and sample processing for analysis were repeated.

\section{Processing of blood and tissue samples}

Blood was centrifuged at $1500 \mathrm{~g}$ for $15 \mathrm{~min}$ at $20^{\circ} \mathrm{C}$. The concentrations of total cholesterol, HDL-cholesterol, LDL-cholesterol and triacylglycerols were determined in serum, whereas lipoprotein fractions were separated by electrophoresis.

Liver and intestine samples were homogenised in $0.14 \mathrm{~mol} / \mathrm{L} \mathrm{KCl}$ on ice with teflon-glass Schütt homogen ${ }^{\text {plus }}$ homogeniser (Schütt Biotec, Göttingen, Germany) at $2800 \mathrm{rpm}$. The tissue mass to buffer ratio was 1:5 (w/v). The homogenates were centrifuged at $10500 \mathrm{rpm}$ 
for 15 min at $4{ }^{\circ} \mathrm{C}$, then GSH-Px activity was determined in the supernatant, lipid substances were extracted from the supernatant (Folch et al. 1957), and concentrations of triacylglycerols, total and free cholesterol, and lipid peroxides were determined. Selenium concentration was determined in the liver before and after fasting, and in small intestine before fasting.

Adipose tissue samples were homogenised in a chloroform and methanol mixture (2:1) (Folch et al. 1957); the tissue mass to mixture ratio was 1:5 (w/v). Tissues were homogenised for $60 \mathrm{~s}$ at room temperature. The homogenates were centrifuged at $3000 \mathrm{rpm}$ for $10 \mathrm{~min}$ at $25^{\circ} \mathrm{C}$, then the concentrations of triacylglycerols, total and free cholesterol, thiobarbituric and reactive substances (TBARS) were determined.

\section{Biochemistry}

Total cholesterol, HDL-cholesterol, LDL-cholesterol and triacylglycerol concentrations and GSH-Px activity were determined by use of Randox reagents (Randox Laboratories, Crumlin, UK) on a SABA 18 biochemistry analyser (AMS, Rome, Italy). The concentration of free cholesterol was determined upon extraction with isopropanol and precipitation with $0.5 \%$ alcohol solution of digitonin (Sobel \& Mayer 1945).

The concentration of lipid peroxides was determined by the method of Trotta et al. (1982) on a Thermospectronic Helios delta spectrophotometer (Unicam, Cambridge, UK). Serum lipoproteins were separated by electrophoresis on celogel strips, while their relations and absolute concentrations of lipoprotein fractions were determined on a Glob-al Scan densitometer (Malta Chemetron, Milan, Italy).

Selenium concentration in homogenates was measured by electrothermal method of atomic absorption spectrophotometry (Matek \& Blanuša 1998).

The concentrations or activity of the study parameters were expressed per gram of tissue.

\section{Statistical data processing}

Results were statistically processed by use of the Statistica 7.1 software (StatSoft Inc., Tulsa, OK, USA) and expressed as X \pm SEM. The significance of differences was assessed by Student's $\mathrm{t}$-test in case of normal distribution (Shapiro-Wilk's test), whereas Mann-Whitney U test was employed if null hypothesis was rejected. The correlation between study parameters was tested by use of the same statistical software.

\section{Results}

\section{Adipose tissue}

Results obtained by determination of lipid concentrations in chicken adipose tissue upon fattening completion and after $48 \mathrm{~h}$ fasting are presented in Table 2. Upon completion of the fattening period, total cholesterol concentration in adipose tissue of Sel Plex group was statistically significantly lower as compared with the values recorded in control group $(P<0.05)$. After $48 \mathrm{~h}$ fasting, a decrease in total and free cholesterol concentrations, and reduced lipid oxidation were recorded in control group $(P<0.05$ all). In this phase, dietary supplementation with organic selenium led to an increase in free cholesterol concentration $(P<0.05)$. 
Table 2

Lipid concentrations in adipose tissue of control and Sel Plex group chicken upon fattening completion and after $48 \mathrm{~h}$ fasting (mean \pm SEM)

\begin{tabular}{lcccc}
\hline & \multicolumn{2}{c}{ After fattening period } & \multicolumn{2}{c}{ After $48 \mathrm{~h}$ fasting } \\
& control & Sel Plex & control & Sel Plex \\
\hline Total cholesterol, mmol $/ \mathrm{g}$ tissue & $244.32 \pm 24.03$ & $118.59 \pm 13.58^{\bullet}$ & $98.73 \pm 5.99^{*}$ & $112.17 \pm 10.18$ \\
Free cholesterol, $\mathrm{mmol} / \mathrm{g}$ tissue & $2.12 \pm 0.22$ & $1.84 \pm 0.23$ & $1.26 \pm 0.12^{*}$ & $2.63 \pm 0.28^{* *}$ \\
Triacylglycerols, $\mathrm{mol} / \mathrm{g}$ tissue & $0.91 \pm 0.08$ & $1.01 \pm 0.06$ & $1.00 \pm 0.07$ & $0.86 \pm 0.08$ \\
Lipid peroxides, $\mu \mathrm{mol} / \mathrm{g}$ tissue & $0.57 \pm 0.13$ & $0.78 \pm 0.33$ & $0.24 \pm 0.08^{*}$ & $0.25 \pm 0.07$ \\
\hline
\end{tabular}

*significant differences between control groups $(P<0.05)$, **significant differences between Sel Plex groups $(P<0.05)$, significant differences between control and Sel Plex groups $(P<0.05)$

\section{Liver}

Liver concentration of triacylglycerols upon fattening completion was lower in Sel Plex group as compared to control group $(P<0.05)$ (Table 3). After $48 \mathrm{~h}$ fasting, an increase in free cholesterol concentration and GSH-Px activity in the liver was observed in both Sel Plex and control groups of animals, along with a decrease in triacylglycerol and selenium concentrations in control group $(P<0.05)$. In addition, fasting resulted in higher GSH-Px activity and higher liver concentrations of selenium and lipid peroxides in control group as compared with Sel Plex group $(P<0.05)$ (Table 3).

Table 3

Lipid concentrations and GSH-Px activity in the liver of control and Sel Plex group chicken upon fattening completion and after $48 \mathrm{~h}$ fasting (mean \pm SEM)

\begin{tabular}{lcccc}
\hline & \multicolumn{2}{c}{ After fattening period } & \multicolumn{2}{c}{ After $48 \mathrm{~h}$ fasting } \\
& control & Sel Plex & control & Sel Plex \\
\hline Total cholesterol, $\mathrm{mmol} / \mathrm{g}$ tissue & $18.67 \pm 1.14$ & $19.62 \pm 0.059$ & $20.55 \pm 0.91$ & $18.29 \pm 0.67$ \\
Free cholesterol, $\mathrm{mmol} / \mathrm{g}$ tissue & $8.41 \pm 0.59$ & $8.44 \pm 0.21$ & $12.63 \pm 0.96^{*}$ & $10.65 \pm 0.26^{* *}$ \\
Triacylglycerols, $\mathrm{mmol} / \mathrm{g}$ tissue & $0.13 \pm 0.01$ & $0.10 \pm 0.01^{\circ}$ & $0.10 \pm 0.01^{*}$ & $0.11 \pm 0.01$ \\
GSH-Px, U/g tissue & $12426 \pm 512$ & $11774 \pm 535$ & $16360 \pm 654^{*}$ & $18315 \pm 501^{* * *}$ \\
Lipid peroxides, $\mu \mathrm{mol} / \mathrm{g}$ tissue & $4.22 \pm 0.37$ & $3.55 \pm 0.28$ & $4.70 \pm 0.16$ & $4.89 \pm 0.15^{* *}$ \\
Selenium, $\mu \mathrm{g} / \mathrm{g}$ tissue & $302.64 \pm 28.36$ & $283.54 \pm 12.81$ & $159.34 \pm 10.68^{*}$ & $302.19 \pm 24.10^{\circ}$ \\
\hline
\end{tabular}

${ }^{*}$ significant differences between control groups $(P<0.05) ;{ }^{* *}$ significant differences between Sel Plex groups $(P<0.05)$; significant differences between control and Sel Plex groups $(P<0.05)$

\section{Small intestine}

Lipid, lipid peroxide and selenium concentrations, and GSH-Px activity in the chicken small intestine are shown in Table 4. Upon fattening, small intestine concentrations of total cholesterol and lipid peroxides were lower in Sel Plex group as compared to control group $(P<0.05)$. Forty-eight hour fasting resulted in increased small intestine concentration of total cholesterol in control group, and increased free cholesterol and triacylglycerol concentrations and decreased GSH-Px activity in both control and Sel Plex groups $(P<0.05)$. After $48 \mathrm{~h}$ fasting, the activity of GSH-Px was higher in Sel Plex group as compared to control group $(P<0.05)$. 
Table 4

Lipid concentrations and GSH-Px activitiy in small intestine of control and Sel Plex group chicken upon fattening completion and after $48 \mathrm{~h}$ fasting (mean \pm SEM)

\begin{tabular}{lrccc}
\hline & \multicolumn{2}{c}{ After fattening period } & \multicolumn{2}{c}{ After $48 \mathrm{~h}$ fasting } \\
& \multicolumn{1}{c}{ control } & \multicolumn{1}{c}{ Sel Plex } & control & \multicolumn{1}{c}{ Sel Plex } \\
\hline Total cholesterol, $\mathrm{mmol} / \mathrm{g}$ tissue & $25.13 \pm 0.67$ & $23.33 \pm 0.57^{*}$ & $26.99 \pm 1.39$ & $28.73 \pm 1.37^{* *}$ \\
Free cholesterol, $\mathrm{mmol} / \mathrm{g}$ tissue & $8.98 \pm 0.26$ & $8.66 \pm 0.22$ & $13.67 \pm 1.38^{*}$ & $15.99 \pm 1.21^{* *}$ \\
Triacylglycerols, $\mathrm{mmol} / \mathrm{g}$ tissue & $0.06 \pm 0.01$ & $0.07 \pm 0.01$ & $0.11 \pm 0.01^{*}$ & $0.12 \pm 0.01^{* *}$ \\
GSH-Px, U/g tissue & $5000 \pm 300$ & $4746 \pm 201$ & $3469 \pm 136^{*}$ & $3871 \pm 116^{* *}$ \\
Lipid peroxides, $\mu \mathrm{mol} / \mathrm{g}$ tissue & $8.78 \pm 0.41$ & $6.77 \pm 0.36^{*}$ & $6.85 \pm 0.39$ & $7.36 \pm 0.41$ \\
Selenium, $\mu \mathrm{g} / \mathrm{g}$ tissue & $120.56 \pm 9.37$ & $109.59 \pm 14.32$ & - & - \\
\hline
\end{tabular}

${ }^{*}$ significant differences between control groups $(P<0.05),{ }^{*}$ significant differences between Sel Plex groups $(P<0.05)$, 'significant differences between control and Sel Plex groups $(P<0.05)$, -: concentration not determined

\section{Serum}

Serum lipid and lipoprotein concentrations are shown in Table 5. Dietary supplementation with organic selenium resulted in lower triacylglycerol and VLDL concentrations upon fattening completion $(P<0.05)$. Forty-eight hour fasting led to a decrease in serum concentrations of triacylglycerols and VLDL in both Sel Plex and control groups, decreased serum HDL concentration in control group, and increased serum LDL concentration in Sel Plex group $(P<0.05$ all). After $48 \mathrm{~h}$ fasting, comparable concentrations of two high-density lipoprotein fractions, HDL and HDL2, were found in both Sel Plex and control groups (Table 5).

\section{Discussion}

Results of this study pointed to a correlation of organic selenium and lipid metabolism in chicken serum and some tissues upon completion of fattening period and their stability against stress induced by $48 \mathrm{~h}$ fasting.

\section{Lipid metabolism and oxidative stability upon fattening completion}

Liver is the main site of lipid synthesis in birds (Hermier 1997). Synthesised triacylglycerols and cholesterol incorporated in lipoprotein particles are transported from the liver to the circulation and peripheral tissues (Tarugi et al. 1989), while triacylglycerols are in part stored in hepatocytes (Hermier 1997). In the present study, organic selenium dietary supplementation led to lower triacylglycerol concentrations in chicken liver upon fattening completion, which is consistent with the findings reported by Asha \& Indira (2004) in guinea pigs. Decreased hepatic triacylglycerol concentrations recorded in the present study were probably due to a reduced hepatic synthesis of triacylglycerols and VLDL, as also demonstrated by their lower serum concentrations (Table 5 ).

The majority of triacylglycerols (Gibbons et al. 2000) and cholesterol (Angel \& Farkas 1974) are deposited in adipose tissue in both mammals and birds (Hermier 1997). Adipose tissue is known to contain lowest levels of selenium (Ullrey 1987), thus the effect of selenium on triacylglycerol and cholesterol metabolism in adipose tissue is likely to result from its influence on lipid synthesis and transport outside adipose tissue. In the present study, dietary supplementation with organic selenium resulted in decreased cholesterol deposition in the chicken adipose tissue. 
Table 5

Lipid concentrations in serum of control and Sel Plex group chicken upon fattening completion and after $48 \mathrm{~h}$ fasting (mean \pm SEM)

\begin{tabular}{lcccc}
\hline & \multicolumn{2}{c}{ After fattening period } & \multicolumn{2}{c}{ After 48-h fasting } \\
& control & Sel Plex & control & Sel Plex \\
\hline Serum lipids & & & & \\
Total cholesterol, mmol/L & $4.81 \pm 0.21$ & $5.04 \pm 0.29$ & $5.27 \pm 0.20$ & $5.03 \pm 0.15$ \\
HDL-cholesterol, mmol/L & $0.89 \pm 0.04$ & $0.98 \pm 0.05$ & $0.97 \pm 0.03$ & $0.91 \pm 0.03$ \\
LDL-cholesterol, mmol/L & $4.42 \pm 0.20$ & $4.65 \pm 0.20$ & $4.86 \pm 0.19$ & $4.74 \pm 0.12$ \\
Triacylglycerols, mmol/L & $0.72 \pm 0.04$ & $0.59 \pm 0.03^{*}$ & $0.28 \pm 0.02^{*}$ & $0.30 \pm 0.03^{* *}$ \\
Serum lipoproteins & & & & \\
VLDL, g/L & $1.30 \pm 0.15$ & $0.87 \pm 0.07^{*}$ & $0.54 \pm 0.17^{*}$ & $0.35 \pm 0.07^{* *}$ \\
LDL, g/L & $1.40 \pm 0.12$ & $1.20 \pm 0.13$ & $1.77 \pm 0.13$ & $1.62 \pm 0.07^{* *}$ \\
HDL, g/L & $3.74 \pm 0.36$ & $4.44 \pm 0.08$ & $3.27 \pm 0.22$ & $3.58 \pm 0.12^{* *}$ \\
HDL 1, g/L & - & - & $2.71 \pm 019$ & $3.03 \pm 0.11$ \\
HDL 2, g/L & - & - & $0.57 \pm 0.08$ & $0.55 \pm 0.07$ \\
\hline
\end{tabular}

*significant differences between control groups $(P<0.05)$, ${ }^{* *}$ significant differences between Sel Plex groups $(P<0.05)$, 'significant differences between control and Sel Plex groups $(P<0.05)$

Besides resorption, the intestine is also involved in lipid and lipoprotein metabolism (Green \& Glickman 1981). Decreased cholesterol concentration in the small intestine of chicken fed a standard diet supplemented with organic selenium may be due to either reduced cholesterol resorption or to faster elimination of resorbed cholesterol in the form of lipoproteins from enterocytes (Green \& Glickman 1981).

Glutathione peroxidase activity depends on selenium concentration in the body (Daun \& Akesson 2004). In our study, dietary supplementation with organic selenium during fattening period had no effect on this enzyme activity or on hepatic and intestinal selenium concentration upon fattening completion, which is in contrast with the findings reported by Cheng et al. (1997) in mouse liver and intestine, and by Arai et al. (1994) and Mahmoud \& Edens (2003) in poultry liver. Upon fattening completion, low intensity lipid peroxidation in the intestine was observed in the group of animals having received organic selenium, probably due to antioxidative properties of selenomethionine (Briviba et al. 1996).

\section{Lipid metabolism and oxidative stability after $48 \mathrm{~h}$ fasting}

Animal exposure to fasting leads to species-specific mobilisation and consumption of energy stores (Yasuhara et al. 1991, Sävendahl \& Underwood 1999, Peebles et al. 2004). In the present study $48 \mathrm{~h}$ fasting led to a decrease in triacylglycerol concentration in both groups of chicken, which is consistent with the findings reported by Lamošová et al. (2004) and Didier et al. (1983) in serum of Japanese quail. As VLDL are the main transport form of triacylglycerols in serum, in our study a reduced serum concentration of triacylglycerols was accompanied by lower VLDL concentration after fasting, which is consistent with the reports by Hermier et al. (1984) in chicken and Lien et al. (2005) in duck. Furthermore, a reduced serum VLDL concentration was associated with an increase in serum LDL concentration in experimental group of chicken, which could be explained by enhanced VLDL breakdown and triacylglycerol consumption as a source of energy. 
Triacylglycerols stored in the liver can be mobilised from the liver in case of enhanced energy demands such as fasting (Lamošová et al. 2004) and laying (Hermier 1997). In the present study, it was observed in the liver of chicken on standard diet after fasting. Similar results are reported by Andriamampandy et al. (1996), who consider the decrease in hepatic triacylglycerols and serum beta-hydroxybutyrate to be a sign of transition from the second to the third fasting stage, i.e. body protein catabolism. In our study, protein breakdown for energy supply could be presumed to have been delayed in order to maintain the hepatic level of triacylglycerols in Sel Plex group stable after fasting.

After $48 \mathrm{~h}$ fasting, small intestine triacylglycerol concentration was increased in both groups of chicken, which could have been related to the presence of triacylglycerol pool in enterocytes as a triacylglycerol store during fasting period (Mansbach \& Nevin 1998).

Organic selenium in the form of selenomethionine and selenocysteine is incorporated into antioxidative compounds and selenoproteins, which serve as a store and source of selenium in stress conditions (Tapiero et al. 2003), as also demonstrated in the present study. Selenium concentration was significantly higher in the liver of chicken fed a selenium-supplemented diet as compared to control group without selenium supplementation. In addition, there was negative correlation between selenium and total cholesterol in the liver of Sel Plex group after $48 \mathrm{~h}$ fasting $(\mathrm{r}=-0.8174 ; P<0.05)$ probably due to a reduced cholesterol synthesis in the liver.

Fasting leads to increased serum cholesterol concentration (Lamošová et al. 2004, Klauda \& Zilversmit 1975, Sävendahl \& Underwood 1999) due to cholesterol mobilisation from adipose tissue (Swaner \& Connor 1975). In the present study, the level of cholesterol in adipose tissue of the Sel Plex group did not change with fasting, thus preventing serum cholesterol concentration to increase due to selenium supplementation.

As significant changes were recorded in adipose tissue concentrations of total and free cholesterol in both groups of chicken after $48 \mathrm{~h}$ fasting without any changes in triacylglycerols, it could be postulated that various lipid components in adipocytes vary independently with fasting (Angel \& Farkas 1974).

The increase in small intestine cholesterol concentration recorded in both groups of chicken after $48 \mathrm{~h}$ fasting was probably consequential to cholesterol resorption from the bile, which is rich in free cholesterol that is easily resorbed (Wilson \& Rudel 1994) because esterified dietary cholesterol accounts for $65 \%$ and biliary cholesterol for $35 \%$ of the cholesterol found in intestinal lumen.

The intensity of lipid peroxidation in chicken blood is reduced with fasting (Piršljin et al. 2006), whereas in the present study it was increased in the liver of chicken fed a seleniumsupplemented diet. The increase in lipid peroxidation concentration was accompanied by an increase in GSH-Px activity in both groups because liver is the main site for elimination of oxidatively damaged lipid molecules transported to the liver by lipoproteins. After fasting, intestinal GSH-Px activity was reduced in both groups, however, with significantly higher values recorded in Sel Plex group. The reasons for this reduction could probably be found in the lack of feed breakdown and of enzyme induction by dietary peroxides, and because the intestine is a source of extracellular GSH-Px, which is necessary for defense against oxidative stress provoked by fasting (Tham et al. 1998). 
In conlusion, organic selenium dietary supplementation influenced the composition and oxidative stability of lipids in serum and tissues of chicken upon fattening completion and led to the following:

- decrease in serum and liver triacylglycerol concentrations upon completion of the fattening period, probably due to a reduced hepatic triacylglycerol and VLDL synthesis;

- decrease in adipose tissue and intestinal cholesterol concentrations due to reduced cholesterol stores and resorption;

- and reduced intensity of lipid peroxidation because of its antioxidative properties.

The effect of organic selenium was also recorded after fasting period and resulted in the following:

- increased free cholesterol concentration in adipose tissue, possibly suggesting selenium involvement in intracellular changes in the total to free cholesterol ratio in stress conditions;

- increased selenium concentration in the liver because of its improved resorption and bioavailability;

- and increased GSH-Px activity in the liver and intestine in response to fasting-induced oxidative stress.

\section{Acknowledgements}

This research was supported by a grant from the Ministry of Science, Education and Sports, Republic of Croatia (No. 053-0531854-1866). The present study was performed according to the Act on Animal Welfare (Official Gazette 135/06) and approved by the Ministry of Agriculture, Fisheries and Rural Development, Republic of Croatia (UP/I 322-01/07-01/59; 525 6-07-2 LJ.Z.).

\section{References}

Asha GS, Indira M (2004) Combined effect of selenium and ascorbic acid on alcohol induced hyperlipidemia in male guinea pigs. Comp Biochem Physiol Part C 137,109-114

Angel A, Farkas J (1974) Regulation of cholesterol storage in adipose tissue. J Lipid Res 15, 491-499

Andriamampandry MD, Bnouham M, Michard D, Gutbier G, Le Maho Y, Leray C (1996) Food deprivation modifies fatty acid partitioning and $\beta$-oxidation capacity in rat liver. J Nutr 126, 2020-2027

Arai T, Sugawara M, Sako N, Motoyoshi S, Shimura T, Tsutsui N, Konno T (1994) Glutathione peroxidase activity in tissues of chicken supplemented with dietary selenium. Comp Biochem Physiol 107A, 245-248

Balicka-Ramisz A, Pilarczyk B, Ramisz A, Wieczorek M (2006) Effect of selenium administration on blood serum Se content and on selected reproductive characteristics of sheep. Arch Tierz 49, 176-180

Briviba K, Roussyn I, Sharov VS, Sies H (1996) Attenuation of oxidation and nitration reactions of peroxynitrite by selenomethionine, selenocystine and ebselen. Biochem J 319, 13-15

Castillo C, Hernandez J, Lopez-Alonso M, Miranda M, Benedito JL (2001) A different point of view of glutathione peroxidase: its relationship to the metabolic changes associated with nutritional management in Assaf ovine breed. Arch Tierz 44, 305-312

Cheng WH, Ho YS, Ross DA, Han Y, Combs GF, Lei XG (1997) Overexpression of cellular glutathione peroxidase does not affect expression of plasma glutathione peroxidase or phospholipid hydroperoxide glutathione peroxidase in mice offered diets adequate or deficient in selenium. J Nutr 127, 675-680

Daun C, Akesson B (2004) Comparison of glutathione peroxidase activity, and total and soluble selenium content in two muscles from chicken, turkey, duck, ostrich and lamb. Food Chem 85, 295-303 
Dhingra S, Bansal MP (2005) Hypercholesterolemia apolipoprotein B expression: regulation by selenium status. Lipids Health Dis 4, 28-40

Didier R, Remesy C, Demigne C (1983) Changes in glucose and lipid metabolism in starved or starved-refed Japanese quail (Coturnix coturnix japonica) in relation to fine structure of liver cells. Comp Biochem Physiol 74A, 839-848

Folch J, Lees M, Sloane Stanley GH (1957) A simple method for the isolation and purification of total lipids from animal tissues. J Biol Chem 191, 833-841

Gibbons GF, Islam K, Pease RJ (2000) Mobilisation of triacylglycerol stores. Biochem Biophys Acta 1483, 37-57

Gradinski-Vrbanac B, Emanović D, Milinković-Tur S, Stojević Z, Župančić Ž, Sušić V, Gregurić J, Dobranić V (1999) Influence of hypothermia on chicken erythrocyte lipid peroxidation in vivo. Vet Med Czeh 44, 129-132

Green PHR, Glickman RM (1981) Intestinal lipoprotein metabolism. J Lipid Res 22, 1153-1173

Hermier D (1997) Lipoprotein metabolism and fattening in poultry. J Nutr 127, 805S-808S

Hermier D, Chapman MJ, Leclercq B (1984) Plasma lipoprotein profile in fasted and refed chickens of two lines selected for high or low adiposity. J Nutr 114, 1112-1121

Holben DH, Smith AM (1999) The diverse role of selenium within selenoproteins: a review. J Am Diet Assoc $99,836-843$

lizuka Y, Sakurai E, Tanaka Y (2001) Effect of selenium on serum, hepatic and lipoprotein lipids concentration in rats fed a high-cholesterol diet. Yakuga Zasshi 121, 93-96

Kolodziej A, Jacyno E (2005) Effect of selenium and vitamin E supplementation on reproductive performance of young boars. Arch Tierz 48, 68-75

Köhrle J, Brigelius-Flohé R, Böck A, Gärtner R, Meyer O, Flohé L (2000) Selenium in biology: facts and medical perspectives. J Biol Chem 381, 849-864

Klauda HC, Zilversmit DB (1975) Cholesterol catabolism in the rabbit in fasted and fed states. J Lipid Res 16, 258-263

Lamošová D, Maáčajová M, Zeman M (2004) Effect of short-time fasting on selected physiological functions in adult male and female Japanese quail. Acta Vet Brno 73, 9-16

Lien TF, Jan DF, Chen KL (2005) Lipoprotein profiles and components in Tsaiya ducks under ad libitum feeding and fasting. Comp Biochem Physiol A 142, 325-330

Mahmoud KZ, Edens FW (2003) Influence of selenium sources on age-related and mild heat stress-related changes of blood and liver glutathione redox cycle in broiler chickens (Gallus domesticus). Comp Biochem Physiol 136, 921-934

Mansbach ii cm, nevin P (1998) intracellular movement of triacylglycerols in the intestine. J Lipid Res 39, 963968

Matek M, Blanuša M (1998) Comparison of two methods for destruction of biological material for determination of selenium. Arh Hig Rada Toksikol 49, 301-305

Milinković-Tur S, Stojević Z, Piršljin J, Zdelar-Tuk M, Poljičak-Milas N, Beer Ljubić B, Gradinski-Vrbanac B (2007) Effect of fasting and refeeding on the antioxidant system in cockerels and pullets. Acta Vet Hungarica 2, 181-189

Peebles ED, Burnham MR, Walzem RL, Branton SL, Gerard PD (2004) Effects of fasting on serum lipids and lipoproteins profiles in the egg-laying hen (Gallus domesticus). Comp Biochem Physiol 138, 305-311

Piršljin J, Milinković-Tur S, Zdelar-Tuk M, Beer Ljubić B, Stojević Z, Gradinski-Vrbanac B (2006) [Effect of fasting and refeeding on blood glutathione and lipid peroxide concentration of cockerels and pullets] Dtsch Tierärztl Wochenschr 113, 453-457 [in German]

Sävendahl L, Underwood LE (1999) Fasting increases serum total cholesterol, LDL cholesterol and apolipoprotein B in healthy, nonobese humans. J Nutr 129, 2005-2008

Sobel AE, Mayer AM (1945) Improvements in the Schoenheimer-Sperry method for the determination of free cholesterol. J Biol Chem 157, 255-264 
Swaner JC, Connor WE (1975) Hypercholesterolemia of total starvation: its mechanism via tissue mobilization of cholesterol. Am J Physiol 229, 365-369

Tapiero H, Townsend DM, Tew KD (2003) The antioxidant role of selenium and seleno-compounds. Biomed Pharmacother 57, 134-144

Tarugi p, reggiani d, ottaviani e, ferrari s, tiozzo r, calandra s (1989) Plasma lipoproteins, tissue cholesterol overload and skeletal muscle apolipoprotein A-I synthesis in developing chick. J Lipid Res 30, 9-21

Temple NJ (2000) Antioxidants and disease: more questions than answers. Nutr Res 20, 449-459

Tham DM, Whitin JC, Kim KK, Zhu SX, Cohen HJ (1998) Expression of extracellular glutathione peroxidase in human and mouse gastrointestinal tract. Am J Physiol (Gastrointest Liver Physiol) 38, G1463-G1471

Trotta RJ, Sullivan SG, Stern A (1982) Lipid peroxidation and haemoglobin degradation in red blood cells exposed to t-butyl hydroperoxide. Biochem J 204, 405-415

Tsopanakis C, Tesserommatis C (1990) Cold swimming stress: effects on serum lipids, lipoproteins and LCAT activity in male and female rats. Pharmacol Biochem Behav 38, 813-816

Ullrey DE (1987) Biochemical and physiological indicators of selenium status in animals. J Anim Sci 65, 17121726

Vinson JA, Stella JM, Flanagan TJ (1998) Selenium yeast is an effective in vitro and in vivo antioxidant and hypolipemic agent in normal hamsters. Nutr Res 18, 735-742

Wilson MD, Rudel LL (1994) Review of cholesterol absorption with emphasis on dietary and biliary cholesterol. J Lipid Res 35, 943-955

Yasuhara M, Ohama T, Matsuki N, Saito H, Shiga J, Inoue K, Kurokawa K, Teramoto T (1991). Induction of fatty liver by fasting in suncus. J Lipid Res 32, 887-891

Received 14 October 2011, accepted 23 April 2012.

Corresponding author:

Blanka Beer-Ljubić

email: bljubic@vef.hr

Department of Physiology and Radiobiology, Faculty of Veterinary Medicine, University of Zagreb, Heinzelova 55, HR-10000 Zagreb, Croatia 